\title{
Are We Too Clean? A History and Analysis of the Hygiene Hypothesis
}

\author{
Riley Steed
}

\section{Abstract}

Since the second half of the 20th century, the incidence of atopic disease has been on the rise. Allergies and rhinitis have become so common that some have called it an epidemic (Strachan, 1989). Initial research into the reasons for the rapid increase was done by David P Strachan, and he proposed the "hygiene hypothesis," a theory claiming that early childhood infections can protect us against atopic diseases later in life (Strachan, 1989). Subsequent research found an interaction between T-helper 1 (Th1) and T-helper 2 (Th2) cells that, for many years, was considered to be the mechanism by which the hygiene hypothesis functioned (Romagnani, 1992). Eventually, it was discovered that this interaction did not work exactly as previously thought, and Graham A. Rook introduced a new theory to match the more recent research. Rook proposed the "old friends" hypothesis, which suggested that certain microbes, which evolved alongside humans, were responsible for protecting us against atopic disease (Rook et al., 2004). According to Rook, modern lifestyles have eliminated many of those microbes from our normal flora, and that explains the recent rise in atopic disease (Rook et al., 2004). The "old friends" hypothesis is now the prevalent atopic disease theory in epidemiology and has helped improve both public and scientific understanding of the relationship between infection, hygiene, and atopy (Stiesma, et al., 2015).

Asthma has a well-documented history going back to famous ancient Greek and Roman scientists Hippocrates, Aretaeus and Pliny. In the later parts of the first century AD, the Greek physician Aretaeus gave this description of an asthma attack: "the cheeks are ruddy, eyes protuberant, as if from strangulation... voice liquid and without resonance... they breathe standing... pale in the countenance, except the cheeks, which are ruddy, sweat about the forehead and clavicles: cough incessant and laborious, and if these symptoms increase, they sometimes produce suffocation" (Marketos \& Ballas, 1982, p. 266). Their understanding of the symptoms was excellent, but unfortunately, they had not yet discovered an appropriate cure. In his book Naturalis Historia, Pliny the Elder wrote that "the most efficient remedy of all is the blood of wild horses taken in drink" (as cited in Bostock \& Riley, 1856, p. 344).

It is now understood that asthma, along with other diseases such as atopic dermatitis, rhinitis and even food allergies, are the result of our bodies producing excessive quantities of immunoglobulin $\mathrm{E}$ ( $\mathrm{IgE}$ ) (Thomsen, 2015). The tendency to produce too much $\lg E$ in response to environment proteins is generally referred to as atopy (Thomsen, 2015). While atopic diseases have long been observed across the world, sometime during the 1960's the incidence of these diseases began to increase at an alarming rate (Bloomfield et al., 2006). As of 2017, the World Health Organization reported that there are around 235 million people worldwide suffering from asthma (World Health Organization, 2017). 


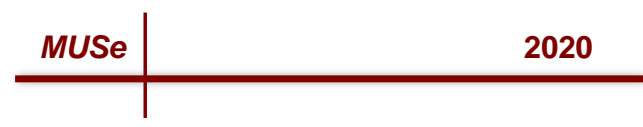

The sudden rise of atopic disease made it an interesting topic for research. In 1989 David P. Strachan found that younger children in a family were less likely to show symptoms of hay fever and suggested that allergic diseases were somehow prevented by infections in early childhood (Strachan, 1989). This theory eventually became known as the hygiene hypothesis, and has been widely discussed ever since (Strachan, 2000).

Strachan's hygiene hypothesis went against some of the literature of the time. In the same year as Strachan's study, W. W. Busse published a review in the journal "Clinical and Experimental Allergy" claiming that infections increased the risk of developing allergic diseases (Busse, 1989). Soon after that, Patrick G. Holt provided some support for Strachan's hypothesis in 1994 when he published an article describing a mechanism by which infections in early childhood could feasibly protect against allergic diseases (Holt, 1994). During the decade following Strachan's initial presentation of the hygiene hypothesis, most scientists supported his idea; in the early 2000 s however, a scientist named G. A. Rook emerged as a vocal opponent to the hypothesis (Rook et al., 2004). Rook has continued his research in immunology and epidemiology and has developed a new theory that he calls the "old friend hypothesis" (Rook et al., 2004).

Strachan was aware of the epidemic levels of hay fever and the drastic increase in cases of asthma that were occurring in the 1980s (Strachan, 1989). His first paper on the subject was short, but important for epidemiology. He examined British epidemiological records of over 17,000 children, as well as the follow up records when the subjects were 23 years old (Strachan, 1989). Strachan found that the likelihood of a test subject suffering from hay fever was inversely related to the number of children living in the household when the subject was 11 years old (Strachan, 1989). Although there was no direct evidence, nor mechanism to explain it, Strachan suggested that early childhood infections actually prevented hay fever (Strachan, 1989). His explanation for the rise in atopic disease was that "declining family size, improvements in household amenities, and higher standards of personal cleanliness have reduced the opportunity for cross infection in young families" (Strachan, 1989, p. 1260). Strachan's "hygiene hypothesis" suggested that modern lifestyles were too hygienic-asthma and allergies were the result of being too clean.

The first evidence to support the hygiene hypothesis did not come until a few years later. By 1992, researchers had discovered an interaction between T helper 1 (Th1) and T helper 2 (Th2) cells that could explain how early-life infection could influence atopic disease later in life (Romagnani, 1992). Research found that the immune system could express more of either Th1 or Th2 cells based on what it was exposed to early on in life (Prete, 1992). If exposed to bacterial or viral infections, that would stimulate production of Th1 cells. Th1 cells would then inhibit production of Th2 cells, and the immune system would become biased towards using Th1 cells (Okada et al., 2010).

In contrast, the absence of microbial infections early in life would cause the immune system to favour Th2 cells (Okada et al., 2010). There are complicated pathways involved in the Th2 immune response, but the upshot is that Th2 cells produce immunoglobulin $E(\lg E)$ in response to allergens, and $\lg E$ is responsible for the symptoms commonly seen in atopic diseases (Okada et al., 2010). This research suggested a mechanism for Strachan's "hygiene hypothesis". A decade after his original publication, scientists had, for the most part, come to 


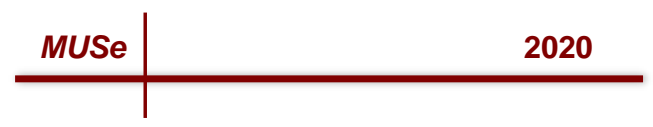

accept the hygiene hypothesis as the most plausible explanation for the rise in atopic disease (Holt et al., 1997).

However, after years of being widely accepted, the hygiene hypothesis came into question near the end of the 20th century, mostly by a researcher named Graham A. W. Rook. Between 2004 and 2012, Rook published four papers arguing against the validity of Strachan's hygiene hypothesis. Rook's first paper in 2004 introduced a new mechanism, which he called the "old friends hypothesis" (Rook et al., 2004). In this paper, Rook provided evidence that the mutually inhibitory effects of Th1 and Th2 cells did not really occur, and that the atopic effects observed in previous research could actually be attributed to malfunction of regulatory T-cells (Treg) (Rook et al., 2004). Rook suggested that it was not early childhood infections that protected against atopy, but exposure to micro-organisms that have co-evolved with humans over hundreds of thousands of years (Rook et al., 2004). These "old friends" eventually became essential components of human immunoregulation: they stimulated the maturation of Treg, and protected us from atopic disease (Rook et al., 2004).

Rook identified three groups of "old friends" that play important roles in his theory. First are saprophytic environmental mycobacteria, which are generally found in mud and untreated water (Rook et al., 2004). Our early hunter-gatherer ancestors would have had extensive exposure to these mycobacteria, but in modern times, our limited exposure to mud and untreated water has eliminated them from the cohort of bacteria normally found in the human gut (Rook et al., 2004). The second group of "old friends" are Lactobacilli, which could be found in many of the stored grain products and fermented drinks used by early humans. Finally, the third group of "old friends" are parasitic worms known as helminths. Infection with helminths is ubiquitous in developing countries, but rare in developed areas, suggesting that it would have been common in primitive man (Biggelaar et al., 2000). There is significant evidence that each of these three groups, when they are part of one's cohort of gut bacteria, provide protection from atopic disease (Zuany-Amorim et al., 2002).

Rook's work was thorough, and he had plenty of evidence to back it up. Although in his first paper he seemed to try to discredit the hygiene hypothesis and replace it with his own "old friends" hypothesis, his later papers tend to describe the old friends hypothesis as an extension and improvement on the hygiene hypothesis. In his second paper published in 2009, he references Strachan's work, and rather than saying it was wrong, he says only that "the concept was initially vague and lacked mechanistic explanations" (Rook, 2009, 3). Eventually, Rook began to use the phrase "hygiene hypothesis". He now uses it to describe his own variation of Strachan's original theory, which focuses more on human evolutionary dependence on microbes, rather than on early-childhood infections (Rook, 2010).

Rook's work helped expand understanding about the role microbes play in immune responses. He has also shown that the hygiene hypothesis has implications not only in allergies, but also in diabetes, inflammatory bowel disease, mental health, Alzheimer's and even cancer (Rook, 2009). The prevalence of these diseases today makes it easy to see why a solid understanding of their causes is so important.

Strachan's original ideas were not quite correct, but they were in the right direction, and his work, like all good science, led the way towards a lot of important research. Unfortunately, his original, incorrect ideas have given rise to some misunderstandings that have persisted until today (Bloomfield et al., 2012). It is an easy leap from "infections in early childhood protect 


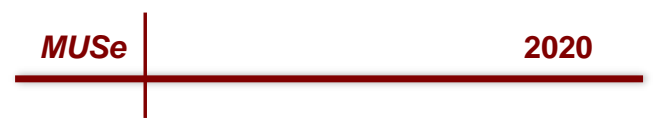

against atopic disease" to "don't teach your kids about proper hygiene, because it will ruin their immune system," and many people made that leap. News headlines like "Keeping children too clean could wreck their immune systems" (Daily Mail, 2012), and "Eating off the floor: How clean living is bad for you" (Scientific American, 2012), reflect the fact that the hygiene hypothesis can easily be misunderstood (Bloomfield et al., 2012). The danger with these misunderstandings is that they make it sound like personal hygiene is, at best, unimportant, and at worst, harmful (Bloomfield et al., 2012). With the exponential growth and urbanization of our communities comes an increased risk of spreading infectious diseases. The most practical and cost-effective solution to prevent infection is to improve personal hygiene, not ignore it (Bloomfield et al., 2012). In a conference in 2012, Sally F. Bloomfield, Ros Stanwell-Smith and Graham A. Rook gave a presentation where they suggested that the key to improving the public's understanding of the hygiene hypothesis is to help them differentiate between letting children play in the dirt, and enforcing hygienic practices, like hand-washing (Bloomfield et al., 2012).

The International Scientific Forum on Home Hygiene (IFH) has now developed an approach they call "targeted hygiene," which focuses hygiene activities (like washing hands) on critical points in the chain of infection (Bloomfield et al., 2016). Although the name "hygiene hypothesis" is likely here to stay, there is work being done that will hopefully be able to improve scientific and public understanding on hygiene's role in important diseases.

Today the hygiene hypothesis, with Rook's amendments, is widely accepted as the cause of several atopic and non-atopic diseases, and a great deal of research is being done to find ways to adapt Rook's theories into cures (Stiesma et al., 2015). Recently, significant progress has been made in the study of live helminth infections as a way to reduce symptoms of atopic diseases, and using probiotics and fecal transplants to protect against rhinitis, allergies and other problems (Stiesma et al., 2015) (Calcinaro et al., 2005).

Future research surrounding the hygiene hypothesis is bright. Strachan's initial hypothesis opened the door to many important discoveries in epidemiology. His original hygiene hypothesis, based on hay fever and family size, may not have been completely accurate, but he had a fruitful idea. Rook was able to take Strachan's ideas, apply more recent data, and create the "old friends" hypothesis. Rook modified the idea that infection could prevent atopy and said that specific microbes have evolved alongside us that are responsible for protecting us from atopic and other diseases. Despite the improved understanding of the hygiene hypothesis in the scientific community, the public has yet to accurately grasp it. The result of the misunderstanding has been a public push against hygiene, based on the belief that we are too clean for our own good. There is considerable work going into improving misconceptions, but this takes time. In the meantime, researchers have begun to do fascinating work, attempting to use microbes and helminths to not only prevent atopic and non-atopic diseases, but also to cure those that already have them. Through the years, the hygiene hypothesis has been rejected, accepted, denied, and changed. But it has survived and stands today as the most plausible explanation for the unanticipated rise of atopic disease. 


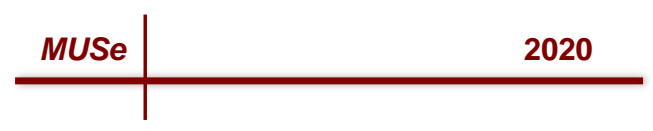

\section{References}

Biggelaar, A. H., Ree, R. V., Rodrigues, L. C., Lell, B., Deelder, A. M., Kremsner, P. G., \& Yazdanbakhsh, M. (2000). Decreased atopy in children infected with Schistosoma haematobium: a role for parasite-induced interleukin-10. The Lancet, 356(9243), 17231727. https://doi.org/10.1016/s0140-6736(00)03206-2

Bloomfield, S. F., Stanwell-Smith, R., Crevel, R. W., \& Pickup, J. (2006). Too clean, or not too clean: the Hygiene Hypothesis and home hygiene. Clinical Experimental Allergy, 36(4), 402-425. https://doi.org/10.1111/j.1365-2222.2006.02463.x

Bloomfield, S. F., Stanwell-Smith, R., \& Rook, G. A. (2012, September). The hygiene hypothesis and its implications for home hygiene, lifestyle and public health: Summary (Rep.).

Retrieved from: https://www.ifhhomehygiene.org/system/files force/publications/Hygiene\%20hypothesis\%20review 1909 2012.pdf

Bloomfield, S. F., Rook, G. A., Scott, E. A., Shanahan, F., Stanwell-Smith, R., \& Turner, P. (2016). Time to abandon the hygiene hypothesis: new perspectives on allergic disease, the human microbiome, infectious disease prevention and the role of targeted hygiene. Perspectives in Public Health, 136(4), 213-224. https://doi.org/10.1177/1757913916650225

Bostock, J., \& Riley, H. T., Esq. (1856). The Natural History of Pliny (Vol. 5). London: Henry G. Bohn.

Busse, W. W. (1989). The relationship between viral infections and onset of allergic diseases and asthma. Clinical Experimental Allergy, 19(1), 1-9. https://doi.org/10.1111/i.13652222.1989.tb02336.x

Calcinaro, F., Dionisi, S., Marinaro, M., Candeloro, P., Bonato, V., Marzotti, S., . . Dotta, F. (2005). Oral probiotic administration induces interleukin-10 production and prevents spontaneous autoimmune diabetes in the non-obese diabetic mouse. Diabetologia, 48(8), 1565-1575. https://doi.org/10.1007/s00125-005-1831-2

Holt, P. (1994). A potential vaccine strategy for asthma and allied atopic diseases during early childhood. The Lancet, 344(8920), 456-458. https://doi.org/10.1016/s0140$\underline{6736(94) 91776-0}$

Holt, P. G., Sly, P. D., \& Björksién, B. (1997). Atopic versus infectious diseases in childhood: a question of balance? Pediatric Allergy and Immunology, 8(2), 53-58. https://doi.org/10.1111/j.1399-3038.1997.tb00145.x 


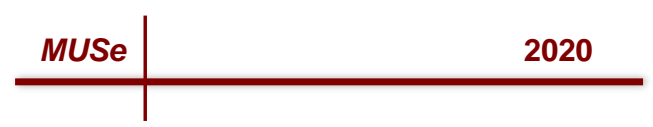

Kalliomäki, M., \& Isolauri, E. (2003). Role of intestinal flora in the development of allergy. Current Opinion in Allergy and Clinical Immunology, 3(1), 15-20. https://doi.org/10.1097/00130832-200302000-00003

Marketos, S. G., \& Ballas, C. N. (1982). Bronchial Asthma in the Medical Literature of Greek Antiquity. Journal of Asthma, 19(4), 263-269. https://doi.org/10.3109/02770908209104771

Okada, H., Kuhn, C., Feillet, H., \& Bach, J. (2010). The 'hygiene hypothesis' for autoimmune and allergic diseases: an update. Clinical \& Experimental Immunology, 160(1), 1-9. https://doi.org/10.1111/i.1365-2249.2010.04139.x

Prete, G. D. (1992). Human Th1 and Th2 lymphocytes: their role in the pathophysiology of atopy. Allergy, 47(5), 450-455. https://doi.org/10.1111/j.1398-9995.1992.tb00662.x

Romagnani, S. (1992). Human TH1 and TH2 Subsets: Regulation of Differentiation and Role in Protection and Immunopathology. International Archives of Allergy and Immunology, 98(4), 279-285. https://doi.org/10.1159/000236199

Rook, G. A. (2009). Review series on helminths, immune modulation and the hygiene hypothesis: The broader implications of the hygiene hypothesis. Immunology, 126(1), 311. https://doi.org/10.1111/j.1365-2567.2008.03007.x

Rook, G. A. (2010). 99th Dahlem Conference on Infection, Inflammation and Chronic Inflammatory Disorders: Darwinian medicine and the 'hygiene' or 'old friends' hypothesis. Clinical \& Experimental Immunology, 160(1), 70-79. https://doi.org/10.1111//.13652249.2010.04133.x

Rook, G. A., Adams, V., Palmer, R., Brunet, L. R., Hunt, J., \& Martinelli, R. (2004). Mycobacteria and other environmental organisms as immunomodulators for immunoregulatory disorders. Springer Seminars in Immunopathology, 25(3-4), 237-255. https://doi.org/10.1007/s00281-003-0148-9

Stiemsma, L., Reynolds, L., Turvey, S., \& Finlay, B. (2015). The hygiene hypothesis: current perspectives and future therapies. ImmunoTargets and Therapy, 2015(4), 143-157. https://doi.org/10.2147/itt.s61528

Strachan, D. P. (1989). Hay fever, hygiene, and household size. BMJ: British Medical Journal, 299(6710), 1259-1260. https://doi.org/10.1136/bmi.299.6710.1259

Strachan, D. P. (2000). Family size, infection and atopy: the first decade of the hygiene hypothesis. Thorax, 55(90001). https://doi.org/10.1136/thorax.55.suppl 1.s2 
Thomsen, S. F. (2015). Epidemiology and natural history of atopic diseases. European Clinical Respiratory Journal, 2(1). https://doi.org/10.3402/ecri.v2.24642

World Health Organization. (2017). Asthma. Retrieved October 31, 2017, from http://www.who.int/mediacentre/factsheets/fs307/en/

Zuany-Amorim, C., Manlius, C., Trifilieff, A., Brunet, L. R., Rook, G., Bowen, G., .. Walker, C. (2002). Long-Term Protective and Antigen-Specific Effect of Heat-Killed Mycobacterium vaccae in a Murine Model of Allergic Pulmonary Inflammation. The Journal of Immunology, 169(3), 1492-1499. https://doi.org/10.4049/iimmunol.169.3.1492 